\section{Hazards of genetic engineering}

SIR-The recommendations contained in a recent report of a West German parliamentary commission on applications of 'genetic engineering' (Nature 325, 474; 1987) are, in some important respects, disquieting. Accompanying the usual ritual praise of the exploitation of 'genes' and the opportunities for more efficient, economic and ecologically beneficial farming and so on is a recommendation for a fiveyear moratorium on planned releases of 'genetically transformed' microorganisms. This is illogical and regressive, and, if adopted, would debilitate important areas of basic and applied research in West Germany. Moreover, adoption would send an ominous, misleading message to regulators and others throughout the world that all genetically manipulated microorganisms are hazardous. On both theoretical and experiential grounds, this is emphatically not so.

There are numerous past examples of successful and beneficial 'releases', or uses, of live organisms in the environment. Important examples include the engineering of non-indigenous crops economically important for food and fibre (for example, soybeans in the United States and high-lysine maize in many parts of the world), and the 'creation' of such hybrids as nectarines, triticale and beefaloes. Insect release has been used successfully to control troublesome weeds in Hawaii and California, and the release of a plant pathogen has been used successfully to control skeletonweed in Australia. More than a dozen microbial pesticidal agents are approved and registered with the US Environmental Protection Agency, and these organisms are marketed in dozens of different products for use in agriculture, forestry and insect control. Bacterial preparations containing Rhizobium, which allow certain plants to produce nitrogen fertilizer from the air, and which thereby promote the growth of leguminous plants (for example, soybeans, alfalfa and beans) have been sold in the United States since the late nineteenth century.

Other 'deliberate releases' include the use of Thiobacillus species, some genetically manipulated, in mining for concentrating certain metals from ores. This has been performed on a vast scale in many parts of the world.

Finally, millions of people each year throughout the world participate, in effect, in 'deliberate release' applications of live attenuated genetically engineered viruses, which undergo replication in the recipient and may be shed. Live human vaccines attenuated by various genetic engineering techniques and now licensed in the United States include mumps, measles, polio and yellow fever. As was the case with the recombinant DNA (rDNA) pseudorabies veterinary vaccine licensed last year by the US Department of Agriculture, rDNA techniques are expected to improve upon both the safety and the efficacy of some of the products at present produced by older methods. US government agencies and the scientific community generally view the techniques of new biotechnology as extensions or refinements of older techniques for genetic manipulation.

The new biotechnological techniques applied to the production of pharmaceuticals have already yielded genuine medical milestones: interferon for the treatment of hairy-cell leukaemia; a monoclonal antibody preparation to prevent rejection of renal transplants; and sensitive tests for the detection of HTLV-III/LAV antibodies, essential to the safety of the world's blood supply. These successes can be replicated in agricultural and environmental applications, but only if prudent, well-controlled testing is performed.

Frank E. Young

Henry I. Miller

Food and Drug Administration,

Rockville, Maryland 20857, USA

\section{Megafauna versus Megafauna}

SIR-As a palaeontologist, C. S. Churcher (Nature 325, 22; 1987) is intrigued by marine biologists' use of the term megafauna, and raises the question of the appropriateness of the terms megafauna and microfauna, proposes a division of invertebrates into size categories and suggests that "...biologists should get the vertebrate megafaunal and microfaunal categories to overlap those of the invertebrates..."

In marine benthos biology, megafauna is a rather inexact term, mainly used in deep-sea contexts. Operational definitions are "animals readily visible in in situ photographs" and "animals sampled by a trawl with part of the bag made of net with a mesh size of $1-2 \mathrm{~cm}$ ". Some authors do not consider megafauna a separate size category but merely a subdivision of macrofauna, which are animals retained by a sieve with 1-mm mesh size.

Microfauna has been used for several size categories of marine benthic organisms, but most common for those larger than bacteria but passing a sieve with about $50-\mu \mathrm{m}$ mesh size. The term is now replaced by nanofauna or the more comprehensive nanobenthos.

The size categories in current use for marine animals include both invertebrates and vertebrates. No division according to size exists for the invertebrates alone. To create one seems inadvisable as there is no need for it and because of the artificiality of the division of metazoa into two groups where one subphylum is opposed to all the rest.

It is desirable that the same prefixes or terms are not used with different meanings in related fields of biology. That situation, however, still exists in marine biology where size categories of plankton and benthos are concerned. A parallel example is the terminology used for terrestrial vertebrate fauna categories and 'biota' of soil biologists. Therefore, to bring marine and terrestrial faunal size categories into line with each other seems a rather remote possibility.

Ole Secher Tendal Zoologisk Museum,Universitetsparken 15, DK 1200 København, Denmark

\section{AIDS agreement}

SIR-We are pleased to note the approaching settlement between the United States government and the Pasteur Institute regarding patent rights related to the discovery of the human immunodeficiency virus (HIV), the virus of AIDS (acquired immune deficiency syndrome).

Dr Luc Montagnier and Dr Robert Gallo and their colleagues are the scientists who contributed most to the discovery of HIV and its relation to AIDS. Their work needs to be celebrated and separated from the legal dispute which is being settled through the clarification of the rights and responsibilities of their respective institutions.

It is important to recognize that the discovery of HIV and its relation to AIDS is only the first step towards the ultimate conquest of this disease. We need to encourage our best scientists, both young and older, to engage in solving the urgent problem posed by the spread of this virus in the human population.

DAVID BALTIMORE (Whitehead Institute for Biomedical Research), BARUJ BENACERRAF (Harvard University), PAUL BERG (Stanford University), JEAN BERNARD (French Bioethics Committee), JEAN Dausset (Collége de France), Renato Dulbecco (Salk Institute), FrançOIS Gros (Institut Pasteur), RoBert Holley (Salk Institute), FrANÇOIS JACOB (Institut Pasteur), Salvador Luria (Massachusetts Institute of Technology), ANDRÉ LWOFF (formerly of Institut Pasteur), JonAS SAlK (Salk Institute), HowARD TEMIN (University of Wisconsin), LEWIS Thомаs (Memorial Sloan Kettering Cancer Center), JAMES WATSON (Cold Spring Harbor Laboratory), JAMES WYNGAARDEN (National Institutes of Health).

Letters submitted for Correspondence should be typed, double-spaced, on one side of the paper only. 